\title{
STRATEGI PENGEMBANGAN FINTECH SYARIAH DENGAN PENDEKATAN BUSINESS MODEL CANVAS DI INDONESIA
}

\author{
Maziyah Mazza Basya (1) Rafi Setya Iqbal Pratama (2) \\ Muhammad Iqbal Surya Pratikto (3) \\ Fakultas Ekonomi dan Bisnis Islam UIN Sunan Ampel (1) \\ Fakultas Ekonomi dan Bisnis Islam UIN Sunan Ampel (2) \\ Fakultas Ekonomi dan Bisnis Islam UIN Sunan Ampel (3)
}

Jl. A Yani 117, Surabaya, Indonesia $\lfloor$ Maziyah.mazza@uinsby.co.id (1)

Rafisetya31@gmail.com (2)

\begin{abstract}
Abstrak : Penelitian ini bertujuan untuk menjelaskan strategi pengembangan Fintech syariah dalam menghadapi persaingan bisnis dengan kompetitor lain. Peneliatian ini menggunakan metode kualitatif dengan pendekatan Business Model Canvas (BMC) yang membahas teori atau mencari referensi yang relevan dengan topik yang di angkat. Peneliti ini menemukan bahwa dalam mengembangkan perusahaan fintech syariah di era disruptif saat ini, harus mempunyai model bisnis yang akan menjadi pondasi dasar dalam menjalankan bisnis berbasis teknologi. Model bisnis tersebut adalah model bisnis kanvas yang memiliki sembilan bagian bangunan, diantaranya: key partnership, key resources, key activities, value proposition, customer segment, customer relationship, channels, cost structure, revenue stream. Namun dalam syariah menambah satu bagian bangunan yaitu syariah compliance. Berdasarkan dari pengelohaan atas pembagian bangunan meemberikan hasil atas strategi pengembangan fintech syariah.
\end{abstract}

Keywords: Fintech syariah, Business Model Canvas 


\section{Pendahuluan}

Di era percepatan teknologi saat ini perkembangan teknologi sedemikian rupa dapat dipastikan memberikan efek resiko cukup tinggi jika tidak dimanfaatkan dengan baik. Dengan adanya teknologi, pemanfaatan terhadap pengelolaan sumber daya alam cukup mudah dan efisien. Masyarakat saat ini telah banyak terpengaruhi dengan adanya percepatan teknologi saat ini, beragam informasi yang didapat dari berbagai fitur menarik dalam tiap gadget (telepon genggam) individu. Hingga, perilaku masyarakat saat ini sangat berubah secara signifikan.

Pada saat ini, perkembangan teknologi yang akan menjadi pembahasan terhangat di Indonesia adalah Teknologi Finansial atau disebut (FinTech). Menurut definisi yang dijabarkan oleh Bank Indonesia, hasil gabungan antara jasa keuangan dengan teknologi yang mengubah model konvensional menjadi moderat (bi.go.id). Saat ini, masyarakat cenderung menyukai terhadap segala sesuatu yang praktis, instan, lebih cepat dan fleksibel. Pada abad ke21 menjadi tahun metamorfosis yang berkesinambungan, dimana perubahan yang menonjol dari hal teknologi dan gaya hidup (lifestyle).

Teknologi keuangan atau Fintech adalah suatu kesempatan yang sangat potensial. Letak geografis yang luas, bisa juga dilihat dari pertumbuhan kelas menengah yang tinggi, sehingga penetrasi produk keuangan yang besar bergabung dalam membuat pasar yang kuat dalam pengembangan fintech di Indonesia. Dengan hanya 36\% dari populasi yang mempunyai rekening bank, fintech di Indonesia menawarkan layanan keuangan yang dapat digunakan kepada penduduk yang belum tersentuh oleh perbankan (unbankable) (Aam, 2019). 
Perkembangan fimtech telah mengalami fluktuatif dari akhir tahun 2019 hingga awal tahun 2020. Akan tetapi, perkembangan terlihat secara signifikan terjadi pada tahun 2015 hingga tahun 2016 yang mana jumlah perusahaan yang menjalankan model bisnis fintech sekitar 165 perusahaan. Fintech sendiri bukanlah suatu layanan keuangan yang ditawarkan oleh lembaga perbankan, tetapi model bisnis baru yang sangat membantu kebutuhan masyarakat. Penyelenggara perusahaan fintech memberikan jasa-jasa dalam membantu masyarakat melayani transaksi tanpa perlu rekening pada lembaga perbankan umumnya. Sehingga, apabila masyarakat melakukan transaksi tidak perlu memberikan identitas pribadi untuk melaksanakan transaksi keuangan. Meski, fintech sendiri bukan dari lembaga keuangan seperti perbankan umum, akan tetapi fintech tetap dalam naungan atau diatur oleh BI dan OJK agar konsumen atau nasabah bisa terlindungi. Oleh sebab itu, perusahaan pengembang fintech harus mendaftarkan perusahaannya pada Bank Indonesia dan Otoritas Jasa Keuangan.

Pada dasarmya, perusahaan startup yang sedang berjalan membutuhkan strategi dalam pengembangannya. Hal ini sama dengan perusahaan fintech untuk meningkatkan usahanya maka perlu mengetahui tentang model bisnis yang akan digunakan. Karena kegiatan perusahaan dapat dikatakan dengan bisnis yang didalamya memiliki sistem, bila sistemnya baik dalam suatu perusahaan maka bisa dipastikan perusahaan tersebut dapat bertahan dalam persaingan bisnis. Di Indonesia terdapat banyak model bisnis, salah satunya adalah model bisnis menjadi konsep utama yang diantara model-model konsep manajemen lainnya. Ketenaran dari model bisnis tersebut dikarenakan mayoritas organisasi perusahaan yang sukses dalam mengembangkan usaha dengan model bisnis yang sesuai. 
Osterwalder dan Pigneur telah mencetuskan konsep model bisnis yang sangat populer yaitu model bisnis kanvas atau lebih dikenal dengan business model canvass. Model ini menawarkan strategi bisnis era 4.0 dalam menghadapi percepatan globalisasi yang dapat menimbulkan permasalahan dalam bisnis. Menurut Osterwalder dan Pigneur (2010) ada sembilan bagian dasar dalam business model canvas. diantaranya dari business model canvas : customer segment, valuepreposition, channels, customer relationship, revenue stream, key resources, key activities, key partnership, dan cost structure.

Business model canvas sangat mendukung perusahaan dalam hal mengetahui dan mengenali apa yang akan menjadi value proposition, hingga bagaimana memdirikan key active dan key resource dalam menciptakan value proporsition dan menghasilkan revenue streams. Kemudian, business model canvas ini juga ada yang menyebutkan perlu ada bagian lagi yaitu tentang ibadah atau yang ke-10. Bagian ini sangat perlu bagi model bisnis syariah, yang mana menjelaskan indikatorindikator ibadah bagi karyawan perusahaan dan calon nasabah. Contoh seperti syariah compliance.

Semua jenis model bisnis akan bisa dilihat sehat atau tidaknya dari laporan keuangan yang dipublikasikan. Hal tersebut, sangat krusial dari suatu perusahaan apabila dari penilaian sehat atau tidak akan menandakan apakah perusahaan ini layak untuk dilanjutkan atau tidak. Business model canvas mempunyai dua bagian pembahasan terkait keuangan dalam bisnis, yaitu revenue stream (arus pendapatan) dan cost structure (struktur biaya). Dimana arus pendapatan memperlihatkan uang yang didapatkan oleh perusahaan. Sedangkan, laporan biaya memperlihatkan biaya-biaya yang wajib dikeluarkan oleh perusahaan.

Dari uraian diatas yang telah dijelaskan, penulis menganalisa dengan adanya perkembangan fintech yang 
semakin pesat di zaman era 4.0 atau serba digitalisasi. Oleh karna itu penulis ingin meneliti lebih dalam serta memberi judul jurnal ini : "Strategi Pengembangan Fintech Syariah Dengan Pendekatan Business Model Canvas di Indonesia" modal di Indonesia.

\section{Landasan Teori}

\section{Financial Technology (Fintech)}

Financial Technlogy merupakan gabungan antara teknologi dan fitur keuangan atau dapat diartikan inovasi pada sektor finansial dengan sentuhan teknologi modern (Pribadiono, Hukum, Esa, \& Barat 2016). Fintech merupakan industri yang berputar dengan cepat dan dinamis dimana terdapat banyak model bisnis yang berbeda. (Miswan, 2019). Fintech adalah sebuah layanan yang menyediakan produk produk keuangan dengan menggunakan dan memanfaatkan teknologi informasi yang mengalami perkembangan yang pesat. Dan juga, Fintech bukanlah termasuk layanan yang telah disediakan oleh lembaga perbankan akan tetapi model bisnis baru yang memanfaatkan kemajuan tekologi yang sangat dapat membantu masyarakat dalam memenuhi kebutuhannya. Jasa maupun produk yang ditawarkan oleh perusahaan fintech guna mendukung masyarakat perihal bertransaksi dalam keuangan tanpa memilki rekening layaknya perbankan. Meski fintech bukanlah lembaga keuangan seperti perbankan akan tetapi telah diatur dalam Otoritas Jasa Keuangan dan Bank Indonesia agar masyarakat terjamin dan terlindungi dalam pelaksanaannya. Oleh karena itu, suatu lembaga keuangan berbasis keuangan harus atau wajib mendaftarkan ke dalam Otoritas Jasa Keuangan (OJK) agar menjadi lembaga yang legal. Jenis dari fintech memang 
memiliki berbagai sektor dari : payment, lending, agregator, crowfunding, personal or financial planning.

2. Financial Technology (Fintech) Syariah

Keuangan syariah merupakan suatu sistem layanan teknologi yang dalam pelaksanaannyaa berdasarkan hukum islam. Pembentukan sistem ini berdasarkan oleh adanya aturan atau hukum didalam agama islam dalam memberikan pinjaman atau mengambil pinjaman yang menggunakan bunga (riba), dan adanya larangan dalam investasi kegiatan usaha yang dilarang (haran) yang belum bisa dijamin dengan sistem konvensional. Dan, sektor pembagian dari fintech syariah masih sama tidak jauh beda dengan fintech konvensial. Fintech Syariah berarti layanan dan solusi keuangan yang diberikan perusahaan teknologi atau start up fintech yang berbasis hukum-hukum islam (syariah). Akan tetapi, regulasi yang dibutuhkan oleh fintevh syariah juga dari Dewan Syariah Nasional - Majelis Ulama Indonesia (DSN-MUI).

\section{Business Model Canvas}

Model bisnis kanvas merupakan bahasa yang sama dalam menggambarkan, menvisualisasikan, menilai, dan mengubah model bisnis. Dari konsep tersebut bisa menjadi bahasa untuk tetap saling berbagai ide yang sering memungkinkan pembaca mendeskripsikan dengan mudah dan memanipulasi model bisnis dalam membuat strategi alternatif baru (Tias, 2019). Model bisnis menggambarkan dasar pemikiran tentang bagaimana organisasi menciptakan, memberikan, dan menangkap nilai Business Model Generation untuk mampu memberikan respons yang cepat terhadap keinginan pelanggan dengan memberikan nilai - 
nilai terbaik yang ada dalam perusahaan (Osterwalder and Pigneur,2010). Business model canvas terdiri dari 9 bagian dan dalam syariah bertambah satu bagian bangunan yaitu:

- Customer segment adalah suatu konsep yang berhubungan langsung dengan untuk menangani pelayanan.

- Value preposition merupakan bagian bangunan yang menggunakan proposisi nilai dalam memecahkan masalah pelanggan dan memuaskan kebutuhan pelanggan.

- Channels adalah salah satu usaha yang menghubungkan pelanggan melalui komunikasi, distribusi dan jalur penjualan.

- Customer relationship yaitu hubungan yang dilakukan oleh pengusaha dengan pelanggan melalui segmentasi pelanggan.

- Revenue stream merupakan bagian bangunan yang menggambarkan tentang semua elemen yang digunakan.

- Key resources adalah bagian bangunan yang menggambarkan kunci kebutuhan pada setiap elemen.

- Key activities merupakan sejumlah aktivitas kegiatan terpenting dalam perusahaan.

- Key partnership adalah suatu penggambaran tentang kegiatan diluar dari sumber daya yang ada.

- Cost structure yaitu bagian blok bangunan yang menggambarkan elemen pendukung strukturisasi biaya.

- Syariah compliance merupakan bagian bangunan antara hubungan pegawai dengan nilai-nilai syariat islam. 


\section{Metode Penelitian}

Pada penelitian ini metode yang digunakan adalah metode deskriptif kualitatif dengan pendekatan Business Model Canvas yang menggunakan data sekunder, data sekunder dalam hal ini pengumpulan data melalui studi literatur, studi pustka dari jurnal, buku, dan website yang terpercaya juga relevan. Metode kualitatif adalah mengumpulkan informasi secara aktual dan terperinci, mengidentifikasikan masalah, membuat perbandingan atau evaluasi dan menentukan apa yang dilakukan orang lain dalam menghadapi masalah dan belajar dari pengalaman mereka untuk menetapkan rencana dan keputusan di waktu mendatang (Suyanto dan Sutinah, 2006) Untuk mengetahui dan memahami tentang strategi pengembangan perusahaan fintech syariah dari pendekatan model bisnis kanvas.

\section{Pembahasan}

Sebuah perusahaan yang sedang berjalan pastinya membutuhkan statregi dalam pengembangan terkait usahanya dalam hal ini, strategi yang harus diperhatikan adalah dari sebuah model bisnis yang terapkan oleh perusahaan tersebut di Indonesia. Hal ini juga berlaku pada seluruh perusahaan, termasuk fintech syariah yang saat ini sedang marak dan masih dominan baru. Dalam perkembangan fintech syariah di Indonesia yang relatif baru ini untuk dapat bersaing dengan perusahaan- perusahaan fintech syariah lainnya dan fintech konvenvional harus memiliki strategi model bisnis yang tepat dan cocok. Dalam penelitian ini terdapat dua lembaga fintech syariah yang digunakan sebagai objek penelitian, yaitu : perusahaan fintech PT. Dana Syariah Indonesia dan PT. Ammana Fintek Syariah. PT Dana Syariah Indonesia adalah lembaga 
keuangan non bank yang berbasis teknologi atau biasa disebut fintech syariah yang didirikan pada akhir tahun 2017 dengan sistem pinjam meminjam langsung tunai atau peerto-peer (P2P) lending yang berprinsip syariah dan diawasi oleh OJK, DSN-MUI. Sedangkan, PT Ammana Fintek Syariah adalah lembaga keuangan non bank yang berbasis teknologi atau biasa disebut fintech syariah yang didirikan pada tahun 2017 dengan sistem pinjam meminjam langsung atau peer-topeer (P2P) lending yang didominasi pada pelaku umkm dengan prinsip syariah dan diawasi sampai terdaftar di OJK tahun 2019 hingga DSN-MUI.

Model bisnis kanvas telah dicetuskan oleh Osterwalder dan Pignuer pada tahun 2012. Dalam model bisnis kanvas terdiri dari 9 bangunan yang terdiri dari key partnership, key activities, key resource, revenue stream, value proporsition, customer relationship, customer segment, cost structure, channels. Akan tetapi, ada satu bangunan penting pada syariah yaitu bangunan syariah compliance atau religiusitas. Berikut ini penerapan model bisnis kanvas pada fintech syariah PT Dana Syariah Indonesia dan PT Ammana Fintek Indonesia.

\section{a. Key Partnership}

- Financial Technology PT Dana Syariah Indonesia

Bangunan key partnership adalah jaringan kemitraan atau pendukung kerjasama usaha, yaitu : Bank BNI Syariah, Mandiri Syariah, dan bank syariah lainnya. Sedangkan, Perusahaan PT Ammana Fintek Syariah juga berkerjasama dengan beberapa dalam mendukung aktivitas usaha, yaitu : Bank BNI Syariah, Mandiri Syariah dan Bank syariah lainnya, Takaful Indonesia, Askrindo Syariah, Jamkrindo Syariah. 
Kemudian, ada kesamaan kerjasama dalam berusaha dari fintech syariah yakni bank syariah yang berada di Indonesia

b. Key Activities

- Financial Technology PT Dana Syariah Indonesia

Bangunan key activities disini menggambarkan aktivitas terpenting yang dilakukan oleh perusahan dimana memberikan produk-produk unggulan dari setiap perusahaan. Perusahaan ini memberikan produk dari pembangunan rumah, renovasi atau pemeliharaan rumah, hingga proyek infrastruktur. Sedangkan dari perusahaan PT Ammana Fintek Syariah memberikan produk- produk unggulan berupa pembiayaan UMKM, pendanaan infak dan wakaf yang bergerak pada sosial. Program tersebut diadakan demi membantu terdampak dalam adanya pandemi covid19.

c. Key Resources

- Financial Technology PT Dana Syariah Indonesia

Bangunan key resources menjadi hal penting dalam menjalankan suatu usaha sebab tanpa adanya sumber daya manusia, maka perusahaan tersbut tidak akan jalan. Dalam hal ini perusahaan dana syariah telah memiliki lender dan borrower sejumlah 104.527 orang dan instansi dari sejak berdirinya perusahaan tersebut. Sedangkan, dari perusahaan PT Ammana Fintek Syariah telah memiliki lender dan borrower sebanyak 3944 yang meliputi perseorangan dan instansi.

d. Value Proposition

- Financial Technology PT Dana Syariah Indonesia 
Bangunan value proposition merupakan proposisi nilai dengan penggabungan antara produk dan layanan yang diberikan oleh perusahaan. Maka dari perusahaan ini, memberikan produk jual beli proyek, pembiayaan dengan prinsip murabahah dan musyarakah. Layanan yang diberikan dalam pendanaan proyek telah diverifikasi oleh tim dana syariah. Tentunya sangat aman dalam pembiayaan. Hingga tetap dalam pengawasan OJK dan DSN- MUI. Sedangkan, dari perusahaan PT. Ammaa Fintek Syariah tmemberi penawaran produk dalam pembiayaan UMKM dengan prinsip syariah (akad mudharabah) atau deposit biller yang menerapkan sistem E-KYC untuk meminimalisir resiko kredit macet. Diawasi dan didukung oleh OJK, Ditjen Dukcapil dan DSN-MUI.

\section{e. Customer Relationship}

- Financial Technology PT Dana Syariah Indonesia

Dalam hal ini, bangunan customer relationship tentang hubungan keterkaitan antara pihak perusahaan dengan pelaku bisnis atau pelanggannya biasa disebut sebagai mitra bisnis dari setiap perusahaan. Dengan memberikan layanan seperti : adanya kepastian dari setiap perjanjian transaksi, keuntungan dan kenyamanan dalam berkomunikasi hingga adanya payung hukum dalam suatu perusahaan. Menjadikan pelanggan akan tetap setia menjadi mitra usaha perusahaan. Sedangkan, dari PT Ammana Fintek Syariah dalam mempertahankan dengan para nasabah, perusahaan telah menjamin penyelesaian masalah dengan kepastian hukum. Menawarkan keuntungan dengan pembagian secara adil sehingga nilai-nilai sosial untuk mensejahterakan para pejuang usaha dapat terealisasi dengan transparan.

f. Customer Segment 
- Financial Technology PT Dana Syariah Indonesia

Pengelompokkan dalam segmentasi pelanggan demi mengetahui adanya perbedaan usia, kelompok organisai dan jangkauan sosial yang mampu dilayani oleh perusahaan. Perusahaan ini memberikan keleluasaan dalam segmentasi pasar yang artinya seluruh penduduk di Indonesia boleh mendaftar menjadi pelanggannya, akan tetapi tetap dengan persyaratan seperti : berusia 18 tahun, memiliki KTP dan mempunyai uang dalam pendanaan. Sedangkan, dalam perusahaan PT Ammana Fintek Syariah juga tidak membatasi secara terperinci, perusahaan memberikan kebebasan sehingga seluruh masyarakat Indonesia menjadi target pasarnya. Total yang menjadi peserta lender sebesar 1656 tersebar dari seluruh penjuru Indonesia.

g. Channels

- Financial Technology PT Dana Syariah Indonesia

Bangunan channels memberikan dampak yang cukup serius karena menjadi proposisi nilai dalam jangkauan komunikasi pelanggan. Membantu sosialisasi perusahaan dari produk hingga edukasi terkait layanan perusahaan Disini, perusahaan menggait beberapa media dari media cetak hingga media elektronik. Telah tergabung dari TVRI, TV ONE, SmartFM, Ras FM, Republika, Antara News dan lain sebagainya. Sedangkan, PT Ammana Fintek Syariah berkerjasama dengan media MNC TV, NET TV, Tirto.id, Tempo.co, Katadata.co.id untuk terus memberikan edukasi dan penawaran-penawaran dari produk usaha perusahaan.

h. Cost Structure 
- Financial Technology PT Dana Syariah Indonesia dan PT Ammana Fintek Syariah

Dari beberapa bagian blok model bisnis kanvas perusahaan memiliki bagian terpenting dalam pembiayaan yang meliputi biaya pemeliharaan gedung, biaya sewa kantor, gaji pegawai dan biaya promosi.

i. Revenue Stream

- Financial Technology PT Dana Syariah Indonesia

Dalam bagian bangunan revenue stream perusahaan tidak mungkin belum memiliki adanya arus pendapatan yang bisa dilihat dari setiap laporan keuangan pertahun. Di perusahaan syariah lebih akrab disebut dengan ujrah atau fee bagi hasil. Imbal hasil dari perusahaan ini berkisar 20\% pertahun, dengan tingkat keberhasilan (TKB) 99.85\% yang bisa disimpulkan memiliki kepastian dan keberhasilan dari setiap transaksi tinggi. Sedangkan, dari perusahaan PT Ammana Fintek Syariah memberlakukan imbal hasil yang cukup besar sekitar $24 \%$ pertahun dan mempunyai tingkat keberhasilan (TKB) cukup baik yaitu 95.37\% .

j. Syariah Compliance

- PT Dana Syariah Indonesia dan PT Ammana Fintek Syariah cukup mempunyai standar dalam tata cara berbusana hingga budaya yang memang menjadi corak sebagai organisasi perusahaan yang berprinsip syariah. Contoh dalam berbusana menggunakan pakaian yang sopan dan berjilbab (untuk perempuan) dan setiap transaksi telah memakai akadakad yang sesuai ketentuan DSN-MUI. 
Setelah dilakukan pemetaan dalam model bisnis kanvas, selanjutnya dilakukan analisis penyusunan strategi dalam pengembangan fintech syariah. Strategi tersebut penyusun menfokuskan pada kegiatan peer-to-peer lending. Berikut strategi yang diperhatikan dalam mengembangkan fintech syariah di Indonesia :

1. Pengoptimalan dari segi sumber daya manusia untuk melakukan inovasi sehingga mampu menjangkau pasar syariah yang sangat luas di Indonesia. Dengan hal, mengadakan training atau workshop dan seminar kepada seluruh pegawai sebagai bentuk optimalisasi sumber daya manusia. Dimana, masih banyak produk-produk yang belum dapat menjangkau dari setiap lini kalangan masyarakat Indonesia.

2. Meningkatkan jumlah lender (investor) dengan menjalin kemitraan atau kerjasama dalam menjangkau para calon lender di seluruh Indonesia. Hal demikian, sangat membantu perusahaan menjadi keunggulan operasional produk.

3. Berupaya meriset inovasi-inovasi produk dalam meningkatkan return atau imbalan yang cukup tinggi sehingga dapat memberikan dampak sosial kepada masyarakat kecil atau anggota lembaga keuangan non bank syariah yang berbasis teknologi.

4. Menjaga kualitas komunikasi dan improvement dengan terus memberikan yang terbaik, sehingga para pelanggan mengalami kenyamanan agar terus dapat berkontribusi dalam perusahaan. 
5. Mendorong lembaga OJK atau terkait bersama lembaga keuangan syariah lainnya untuk memberikan regulasi khusus fintech syariah kepada pihak-pihak yang terkait. (Wibowo, Budi dan Kusnadi, Irwan. 2016.)

6. Memberikan edukasi yang secara jelas atau terperinci antara bedanya riba dan bagi hasil kepada masyarakat terutama bagi generasi milenial yang sedang mengalami bonus demografi. Hal tersebut perlu diperhatikan agar bisa merembah keikutsertaan.

7. Melaksanakan sosialisasi tentang keuangan bersama DSN-MUI hingga stakeholder lainnya contoh Asosiasi Fintek Syariah Indonesia dan memberikan pelatihan kepada mitra agar melakukan kegiatan usaha sesuai rencana kerja dan sesuai dengan standar operasional perusahaan (SOP) dalam pembiayaan $\mathrm{p} 2 \mathrm{p}$ lending

8. Menjalin kerjasama dengan lebih banyak lembaga keuangan syariah, baik mikro maupun makro agar bisa menjadi lender untuk meringankan resiko yang akan terjadi di waktu mendatang.

\section{Penutup}

Lembaga keuangan syariah non bank berbasis teknologi memiliki potensi dalam perkembangannya dari faktor internal hingga eksternal memberikan kekuatan sendiri dengan menggunakan strategi bussines model canvas yang menfokuskan pengoptimalan internal dari perusahaan untuk 
mendapatkan manfaat peluang bisnis di tengah masyarakat Indonesia dimana jumlah masyarakat muslim yang lebih mendominasi penduduk Indonesia dan generasi milenial yang melek akan keuangan digital. Akan tetapi, kekuatan yang dimiliki oleh perusahaan harus diperbaiki dan dilakukan inovasi agar dapat bersaing dengan kompetitorkompetitor lainnya.

\section{Daftar Referensi}

Agustiawati, T. (2019). Perbandingan Business Model Canvas Pada Financial Technology Konvensional Dan Syariah Di Indonesia (Bachelor's thesis, Fakultas ekonomi dan bisnis uin jakarta).

Ansori, M. (2019). "Perkembangan Dan Dampak Financial Technology (Fintech) Terhadap Industri Keuangan Syariah Di Jawa Tengah". Wahana Islamika: Jurnal Studi Keislaman.

A. Osterwalder and Y. Pigneur, (2010). Business model generation: a handbook for visionaries, game changers, and challengers: John Wiley \& Sons,

Bank Indonesia. (2016). “Booklet Keuangan Inklusif”. Jakarta, Departmen Pengembangan Akses Keuangan dan UMKM Bank Indonesia

Hartatik, H., \& Baroto, T. (2017). Strategi Pengembangan Bisnis Dengan Metode Business Model Canvas. Jurnal Teknik Industri, 18(2), 113-120. 
Hiyanti, H., Nugroho, L., Sukmadilaga, C., \& Fitrijanti, T. (2020). Peluang dan Tantangan Fintech (Financial Technology) Syariah di Indonesia. Jurnal Ilmiah Ekonomi Islam, 5(3), 326-333.

https://www.danasyariah.id/ https://app.ammana.id/

Mujahidin, M. (2019). Opportunities and Challenges of Sharia Technology Financials in Indonesia.

Setyaningsih, E. D. (2018). Analisis SWOT Implementasi Financial Technology Syariah pada PT Telkom Indonesia. Syiar Iqtishadi: Journal of Islamic Economics, Finance and Banking.

Suyanto B dan Sutinah, (2006), Metode Penelitian Sosial, Jakarta : PT Kencana Persada

Wibowo, Budi dan Kusnadi, Irwan, (2016). Analisa Regulasi Fintech Dalam Membangun Perekonomian Di Indonesia,

Wilis, R. K. (2020). Analisis SWOT Teknologi Finansial pada Transformasi Perbankan di Era Digital (Studi Kasus pada Bank X di Jakarta) (Doctoral dissertation, Universitas Muhammadiyah Surakarta) 